Please quote as: Oeste-Reiß, S.; Söllner, M. \& Leimeister, J. M. (2016): Development of a Peer-Creation-Process to Leverage the Power of Collaborative Knowledge Transfer. In: Hawaiin International Conference on System Sciences (HICSS), Kauai, Hawaii, USA. 


\section{Development of a Peer-Creation-Process to Leverage the Power of Collaborative Knowledge Transfer}

\author{
Sarah Oeste-Reiß \\ Information Systems, \\ Kassel University \\ sarah.oeste@uni-kassel.de
}

\author{
Matthias Söllner \\ Information Systems, \\ Kassel University \\ soellner@uni-kassel.de \\ Institute of Information \\ Management, \\ University of St. Gallen \\ matthias.soellner@unisg.ch
}

\author{
Jan Marco Leimeister \\ Information Systems, \\ Kassel University, \\ leimeister@uni-kassel.de \\ Institute of Information \\ Management, \\ University of St. Gallen \\ janmarco.leimeister@unisg.ch
}

\begin{abstract}
The effective transfer of existing knowledge among employees becomes increasingly important for organizations in order to remain competitive on the market. Even though the digital age allows for new ways of team collaboration, there are still unsolved problems in terms of knowledge transfer. Thus, knowledge activities as well as aspects of tool support need to be analyzed. Hence, we develop a peer-creation-process (PCP) that provokes knowledge transfer in several ways. There is a transfer of knowledge from experts to novices and among the experts, resulting in a high-quality knowledge document. We ground our research on insights from collaborative learning and collaboration engineering to develop and evaluate the PCP. We contribute to theory and practice by providing a theory for design and action, with the PCP design leveraging the power of knowledge transfer. We illustrate that our PCP is applicable with, and without, IT-support and give differentiated implications.
\end{abstract}

\section{Introduction}

The level of employee turnover in organizations increases as a consequence of demographic change and job rotation. With the advent of the digital age and the ubiquity of information, employees need to be aware of factual knowledge, reflecting, and applying that knowledge as well as improving soft skills such as teamwork, communication, cooperation, and critical thinking [1]. In order to remain competitive in the market, the productive transfer and retention of knowledge among employees become increasingly important [2]. Consequently, in order to effectively stimulate a transfer and retention of knowledge between people, collaborative learning activities need to be addressed. Until now, knowledge activities often fail, since knowledge transfer often takes place unconsciously or due to shortcomings of existing approaches. Either such knowledge activities lack an additional benefit for the employees such as a knowledge gain, or knowledge documentations are incorrect or incomplete. In addition, employees often are not proactively involved in such knowledge activities and perceive the applied technologies as complex. Consequently, the employees decline such knowledge activities. In this context, the central problem constitutes the way that transfer of knowledge becomes managed since this has the potential to simultaneously document valuable knowledge.

Since knowledge activities underlie collaborative learning activities, existing research in the context of collaborative learning, addresses methods such as peer questioning and peer discussions in order to enhance structured interactions [3] and foster knowledge transfer between learners. This, however, focuses only on discussions and lacks a common outcome in the form of knowledge documentation. The learning interactions in such a collaborative learning process can often only be structured up to a certain degree. In order to provide guidance for learners' interaction, so-called collaborative learning scripts are existent. They address interaction sequences between learners and give precise instructions on how to interact with each other [3-5]. However, the focus is on enhancing learning success rather than on generating common output, such as knowledge documentation. Nevertheless, they provide guidance on managing the process of collaborative learning activities.

From an organizational point of view, transfer as well as documentation of knowledge is crucial. Knowledge documentations have the potential to allow knowledge transfer to other employees who are 
not able to participate in collaborative interactions with other employees. In such context, collaboration engineering (CE) provides a promising starting point in order to purposefully manage the collaboration between the involved people towards a common outcome such as a knowledge documentation. In comparison to the work of individuals, groups have the potential to outperform individuals, who usually lack knowledge or experience for solving complex tasks [6]. The resulting interaction among individuals stimulates knowledge production, produces cognitive gains and, improve people's soft skills [3]. However, the focus of CE is more on managing collaborative activities than on enhancing individual learning. Thus, in the context of CE insights, collaborative learning needs to be respected. After all, this can lead to retaining knowledge in the form of documentations, since individuals can work on common material.

In this paper, we close that research gap in order to foster structured knowledge transfer and documentation among employees. Thus, we aim to answer the research question of how to design a collaborative process for transfer and documentation of knowledge. To answer this question, we combine methods from CE with insights from collaborative learning. We develop a re-usable collaborative group process, which we call the peer-creation-process (PCP). The intention of the PCP is to stimulate knowledge transfer among people, resulting in individual benefits in the form of individual knowledge gains and common outcomes in the form of knowledge documentations. Our PCP resembles a theory of design and action, since it provides guidance on how to leverage the benefits of knowledge transfer while respecting requirements from collaborative learning in the PCP design. Since it is a new solution to a known problem, it also resembles a contribution of the 'improvement' type [7].

\section{Design science research approach}

The aim of our study is to develop a PCP which promotes knowledge transfer and documentation with guidance on how to apply the PCP in scenarios with different tool support (offline vs. online). In line with Gregor [7], we aim to derive a nascent theory for design and action inherent to the PCP. In order to achieve this goal, we structure our study by using Hevner's design science research framework [7, 8].

As Figure 1 depicts, we first identified the lack of solutions for systematic knowledge transfer in the upper half of the relevance cycle (see section 1). Based on the problem definition, we deducted the objectives for an artifact in the form of the PCP to solve this problem.

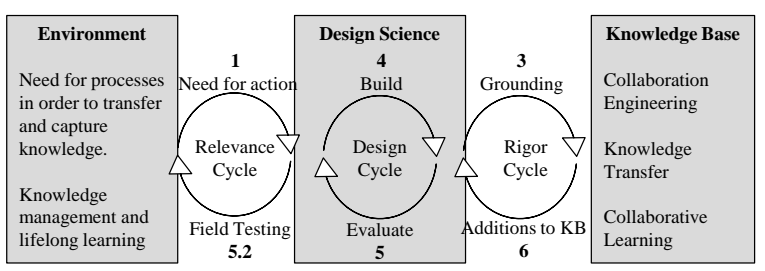

Figure 1. Design science cycles

In addition, we studied CE methods and collaborative learning in order to develop a first version of the PCP. We completed a rigor cycle by grounding the design on scholarly literature from the fields of CE (section 3.1), knowledge transfer (section 3.2), and collaborative learning (section 3.3). The intention was to inform our design choices in order to report a nascent theory for design and action embodied in the PCP and trace it back to the research community. Driven by the needs from the practical problem situation, we completed the design cycle. We designed the PCP as well as iteratively tested it as a generalizable solution and also considered its readiness for being used in an organizational setting (see section 4). We took the PCP back into the field to test it in the pilot test with real-problem stakeholders such as (see section 5): experts in CE, collaborative learning, moderators, and students as participants. We decided to use students for the pilot test since we needed to ensure that our PCP worked before we could apply a broad rollout in organizations. Since we can expect that the knowledge levels vary among all students, students are a good substitute for the test [9].

As the PCP is a complex task in real-world settings and no conclusive body of theory is existent on how to systematically develop re-usable mechanisms for knowledge transfer and documentation, we chose an exploratory research design to allow for unexpected findings and flexible design adaptions [10]. In order to allow for a holistic view and compensate for the weaknesses of individual data collection, we selected a triangulation of design validation methods. While we completed the relevance cycle, this validation showed that the designed artifact would be suitable for solving the defined problem in our evaluation setting. In addition, it provided an indication that the PCP design was ready to be used in an organizational setting. We analyzed the use of the PCP in this instantiation in order to evaluate its effectiveness. We used insights from the design validation to iterate them in the design phase in order to give recommendations for design improvements, practical notes for the use of the PCP, as well as tool support. With 
this design science study, we contribute to $\mathrm{CE}$ research in collaborative learning by providing a new solution for leveraging the benefits of knowledge transfer. As de Vreede et al. [11] point out in their research agenda, we additionally give theoretical insights into how to apply a collaborative process design (such as the PCP) in offline and online scenarios. Our practical contribution is embedded in knowledge management practice.

\section{Related Work}

\subsection{Collaboration Engineering}

A detailed design methodology is necessary to focus collaborative activities on the stimulation of knowledge transfer. The design methodology should provide procedural guidance on how to systematically split structure and to describe collaborative activities for the transfer and documentation of knowledge. It should lead to a PCP that is easily understandable and applicable with different tool support. In addition, it should facilitate collaborative learning processes to reliably improve reflection and application of knowledge as well as soft skills. CE is an approach for designing collaborative work practices for high-value recurring tasks, and deploying them without the ongoing support from a professional facilitator or collaboration engineer [12]. In that case, collaboration can be described as the work of two or more people on common material, which is characterized by coordination, communication, and cooperation [13]. Table 1 depicts the applicability of CE in the context of our study. The left column represents the criteria for using CE as a design methodology [13]; the right column describes the context of the PCP in our study and explains the suitability of CE:

Table 1. CE in the context of the PCP

\begin{tabular}{|l|l|}
\hline $\begin{array}{l}\text { Collaboration } \\
\text { Engineering }\end{array}$ & Context of the research artifact (PCP) \\
\hline $\begin{array}{l}\text { Collaborative work } \\
\text { practice }\end{array}$ & $\begin{array}{l}\text { In the form of activities for transferring and capturing } \\
\text { knowledge as well as stimulating knowledge gains. }\end{array}$ \\
\hline High value task & In order to be competitive on the market. \\
\hline Recurring task & In the context of employee turnover. \\
\hline Collaboration engineer & Designer of the PCP (researchers of the paper). \\
\hline Facilitator & Person with moderation skills. \\
\hline Practitioner & Participants in the form of employees, learners. \\
\hline
\end{tabular}

In order to design the PCP in a structured and reusable way, we use the Collaboration Process Design Approach (CoPDA) [14] as specific CE methodology. The use of the CoPDA helps us to split knowledge transfer tasks into concrete activities and derive a re-usable PCP design. The CoPDA consists of five steps: Task diagnosis as first step includes an analysis of task, stakeholders, and resources. It ends with the definition of goals and products (outcomes) of the collaborative process [14]. The second step addresses task decomposition. Depending on the goals and products, sub products with appropriate activities are defined. These must a group do in order to fulfill the common goal. Group procedures such as the patterns of collaboration (PoC) [generate, reduce, clarify, organize, evaluate, and build consensus] help to structure collaborative interactions. Step three focuses on the thinkLet choice. A thinkLet is a named, scripted, re-usable, and transferable sequence of collaborative activities [12] that serves as a building block for collaborative process designs. Step four addresses the agenda building that consists of developing an internal agenda with specific questions and instructions for every activity as well as a facilitation process model (FPM) that gives an overview of the collaborative process. In step five follows a design validation [14].

\subsection{Knowledge transfer}

As described in section 1, organizations face problems of knowledge transfer in order to remain competitive in the market. In that context, factual knowledge becomes decreasingly important, while the importance of tacit knowledge, such as procedural knowledge, increases. Procedural knowledge focuses on how to do something, methods of inquiry, criteria for using skills, techniques, and methods [15]. In comparison to factual knowledge, such knowledge is more valuable, since it is often only visible in an indirect manner, such as actions by a person or within a certain context [16]. Social interactions between at least two people take place in order to enhance a transfer of knowledge [17].

Figure 2 depicts a working definition of knowledge transfer, since the transfer of procedural knowledge requires social interactions, collaboration between at least two people is necessary [16]. This collaboration has the potential to enable exchange, reflection, and application of knowledge [18]. Consequently, knowledge transfer can occur in two ways. First, a direct knowledge transfer among the involved people can occur in the form of knowledge gains. The involved people acquire knowledge as well as improve their soft skills such as teamwork, communication, cooperation, or critical thinking. Second, an indirect knowledge transfer can occur through the knowledge documents that the involved people develop during their collaboration with each other. The knowledge becomes retained and serves as a resource of indirect knowledge transfer for third parties. 


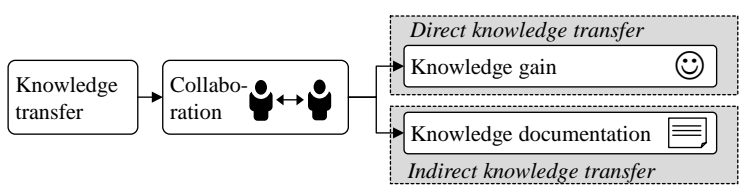

Figure 2. Definition of knowledge transfer

This paper focuses on how the collaborative process for knowledge transfer is designed and managed in order to foster knowledge gain for the involved people as well as to empower the involved people to document their knowledge in an appropriate way.

\subsection{Collaborative learning}

From an educational point of view, constructivist learning theory provides useful basics for our problem. It focuses on people who are learning from experience. Individuals are actively involved in learning activities during social interactions with other learners [18]. During the collaboration with others they reflect and apply knowledge, as well as improve their soft skills. The work of Moore [19] differentiates between three interaction types: learner-learner interaction, learner-lecturer interaction, and learner-content interaction. We consider these interaction types, because interaction provokes learning activities that demand an exchange between learners, lecturers, and content [19]. Learners who interact with lecturers are more actively involved and receive a higher degree of knowledge gain compared to those who do not interact. The question-answer game is the classic form of learner-lecturer interaction. Learners have the opportunity to contribute their ideas and thoughts as well as request clarification of unclear issues. The learner-learner interacttion enables a direct exchange and fosters the individual reflection ability. Feedback on one's own performance leads to an awareness and an understanding of how to control their learning. Conversations and discussions increase learner motivation [20] and learning success [21]. Learner-content interacttion takes place by examining learning content, e.g., in the form of text, audio, or video [21].

The interaction types give important insights into why interaction is necessary for learning performance. In that context, collaborative learning and related forms aim to elicit different learner activities and address the three interaction types. Collaborative learning is an instruction method in which learners work in groups [3]. Learners help each other, provide guidance and, monitor their understanding. They work independently at different stages, interact with each other, and conduct joint work in larger groups [22]. Reciprocity in the social interactions is necessary to ensure feedback between learners [23]. This fosters the development of critical thinking, clarification of contributions, assessing others' contributions, as well as improving soft skills such as teamwork, communication, cooperation, or critical thinking. In addition, the learners become responsible for their activities [24] while a lecturer guides them and communicates explicit expectations [23]. Focusing on the outcome of collaborative learning activities leads to peer creation. An outcome can be knowledge gain or knowledge documentation. From that point of view, peer creation always takes place in the context of collaborative learning. Peer creation literature provides useful mechanisms for the co-creation of knowledge. Learners add their knowledge to the learning content. In doing so, a clear assignment and focused instructions are necessary. The lecturer has to make learners accountable for their work [25]. Focusing on the assignment structure, cooperative learning provides additional insights. In small groups of up to six people, learners solve assignments. These are divided into subtasks, from which successive tasks follow. The learners are dependent on each other and are accountable for their actions [25]. In order to provide direct feedback to the learners as well as ensure correction mechanisms, peer review gives some additionnal hints. Learners assess one another's work and give each other feedback [26]. In order to ensure constructive feedback, the lecturer provides explicit feedback criteria. A peer review enables a wide range of feedback perspectives [26].

\section{Conceptual development of the PCP}

In this section 4, we develop the design of the PCP. The PCP aims to design collaborative learning activities in a systematic and re-usable way in order to provoke knowledge transfer. During the collaboration with each other, the practitioners receive an individual knowledge gain and codify their procedural knowledge. Since a knowledge document will be the collaborative outcome of the PCP, we discuss below which kind of knowledge document is appropriate to codify procedural knowledge. In section 4.1 we derive educational requirements and in section 4.2 we describe the design of the PCP. The knowledge document should serve as resource for an indirect knowledge transfer for third parties. As described in section 3.2, the transfer of procedural knowledge has an explanatory character. Therefore, the knowledge document should also address this characteristic. In such context, explanation videos, respectively, the storyboards for explanation videos, are knowledge documents that have the potential to convey this claim. They explain a solution for a complex problem 
in an easily understood language with short sentences enriched with visual animations [27]. The development of an explanation video requires a storyboard. The storyboard contains all relevant knowledge and requires a precise examination and reflection of the knowledge. It documents the explanation of knowledge in the form of text and visualizations. For that reason, the collaborative outcome of the PCP is a storyboard which documents the procedural knowledge of the practitioners.

\subsection{Requirements}

Theory-driven, we derive educational requirements from collaborative learning in order to enhance knowledge transfer. The requirements are derived from the related work section 3.3 and will be respected in the PCP design.

\section{Table 2. Educational requirements}

\begin{tabular}{|c|c|c|}
\hline Int. & \multicolumn{2}{|c|}{ Requirements from collaborative learning } \\
\hline \multirow{6}{*}{ 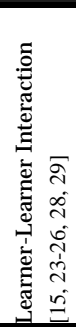 } & $\mathrm{R}_{1}$ & $\begin{array}{l}\text { Group formation: Put together a group of learners and } \\
\text { reconcile them on the same knowledge. }\end{array}$ \\
\hline & $\mathrm{R}_{2}$ & $\begin{array}{l}\text { Reciprocity: Foster social interactions between learners by } \\
\text { providing proper tools and assignments. }\end{array}$ \\
\hline & $\mathrm{R}_{3}$ & $\begin{array}{l}\text { Interdependence: Ensure positive interdependence } \\
\text { between learners through tools and assignments. }\end{array}$ \\
\hline & $\mathrm{R}_{4}$ & $\begin{array}{l}\text { Accountability: Use social pressure to make learners } \\
\text { accountable for their activities. }\end{array}$ \\
\hline & $\mathrm{R}_{5}$ & $\begin{array}{l}\text { Group dynamics: Constitute a positive group atmosphere } \\
\text { by empowering learners to add value to their activities. }\end{array}$ \\
\hline & $\mathrm{R}_{6}$ & $\begin{array}{l}\text { Objectives: Ensure focused learner activities by providing } \\
\text { objectives for structuring them. }\end{array}$ \\
\hline \multirow{5}{*}{ 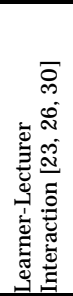 } & $\mathrm{R}_{7}$ & $\begin{array}{l}\text { Lecturer: Provide a lecturer to escort the learners though } \\
\text { their activities. }\end{array}$ \\
\hline & $\mathrm{R}_{8}$ & $\begin{array}{l}\text { Expectations: Communicate explicit expectations to } \\
\text { learners to ensure focused activities. }\end{array}$ \\
\hline & $\mathrm{R}_{9}$ & $\begin{array}{l}\text { Feedback: Give learners direct feedback about their } \\
\text { learning progress. }\end{array}$ \\
\hline & $\mathrm{R}_{10}$ & $\begin{array}{l}\text { Constructive Feedback: Ensure constructive feedback by } \\
\text { providing feedback criteria. }\end{array}$ \\
\hline & $\mathrm{R}_{11}$ & $\begin{array}{l}\text { Reflection: Ensure discussions between learners by means } \\
\text { of discussing the solution of an assignment with other } \\
\text { learners. }\end{array}$ \\
\hline \multirow{6}{*}{ 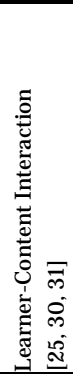 } & $\mathrm{R}_{12}$ & $\begin{array}{l}\text { Type of assignment: Provide an assignment for learners to } \\
\text { solve alone before discussing it in the group. }\end{array}$ \\
\hline & $\mathrm{R}_{13}$ & $\begin{array}{l}\text { Assignment structure: Divide assignments into subtasks } \\
\text { which build on each other. }\end{array}$ \\
\hline & $\mathrm{R}_{14}$ & $\begin{array}{l}\text { Assignment wording: Define assignments clearly and } \\
\text { understandably. }\end{array}$ \\
\hline & $\mathrm{R}_{15}$ & $\begin{array}{l}\text { Structure of outcome: Pay attention to a logical and } \\
\text { consistent way of documentations by providing templates } \\
\text { for learner activities. }\end{array}$ \\
\hline & $\mathrm{R}_{16}$ & $\begin{array}{l}\text { Complexity of outcome: Pay attention to an easily } \\
\text { understandable language of collaborative outcomes. }\end{array}$ \\
\hline & $\mathrm{R}_{17}$ & $\begin{array}{l}\text { Correctness of outcome: Ensure correctness of } \\
\text { collaborative outcomes by means of proofreading and } \\
\text { feedback mechanisms. }\end{array}$ \\
\hline
\end{tabular}

\subsection{Design of the peer-creation-process}

The design development of the PCP as a re-usable and structured collaborative process followed the CoPDA (see section 2.2) [11] and respects the educational requirements (see section 4.1). In CE a design development starts with a definition of the common goal. In the context of the PCP, this can be described as follows: "Practitioners transfer and document their procedural knowledge in the form of collaboratively developing a storyboard for an explanation video within the next six hours." The description of the PCP design includes a FPM (see Figure 3) and an internal agenda (see Table 3). Required preparation for the facilitator is to provide the knowledge topics. The size of the whole group (max. 15 practitioners) and the granularity of the subtasks per assignment (maximum five categories [number of categories = number of subgroups]) determines the time needed for applying the PCP (about 6 hours).

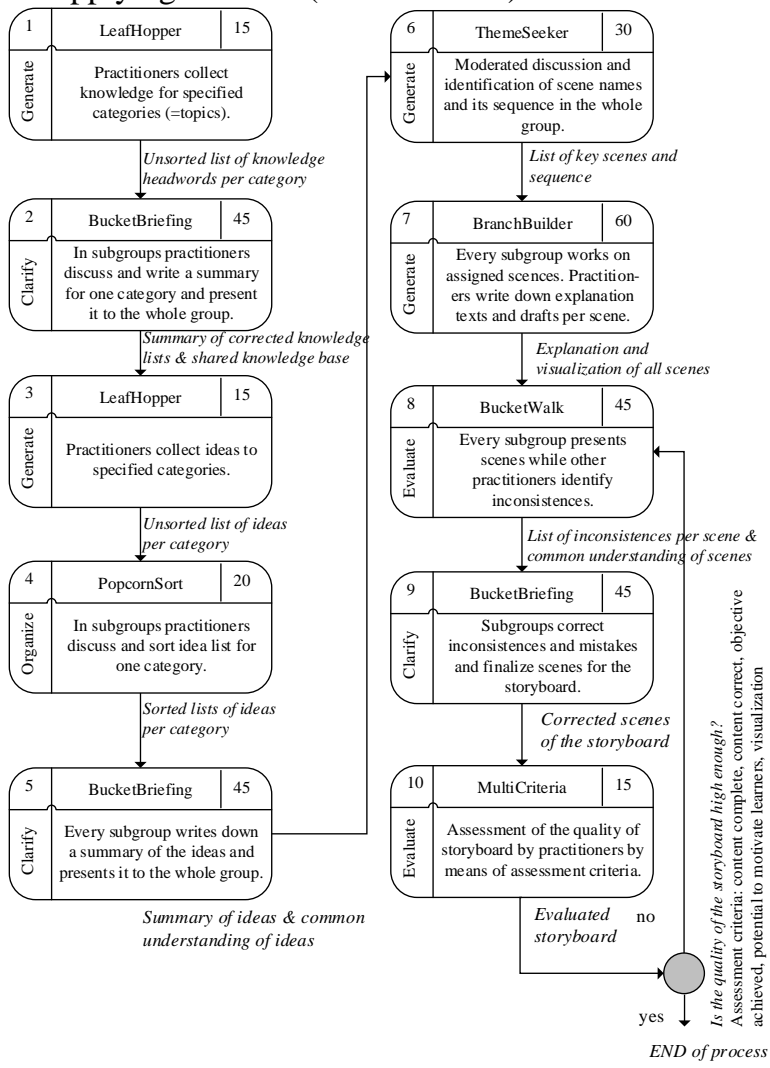

Figure 3. FPM of the peer-creation-process

The FPM (see Figure 3) gives an overview of the PCP and depicts all collaborative products and the sequence of activities. Activities 1 and 2 focus on reflecting knowledge in general. The corresponding intention is to clarify relevant knowledge and generate a shared understanding. The focus of activities 3 to 5 is to create a rough concept, clarify the focus of the storyboard, and organize first ideas. In order to structure the ideas, a storyline with key scenes is developed during activity 6 . With this in mind, the refined concept of the storyboard is developed in activities 7 to 9. By means of several evaluations, the correctness of the documented knowledge is ensured. Activity 10 gives insights into whether the collaboration ends or refinement is needed. 
Table 3. Internal agenda of the PCP

\begin{tabular}{|c|c|c|c|c|c|c|c|c|c|c|c|}
\hline 5 & & 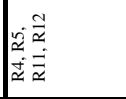 & 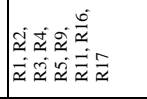 & 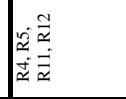 & 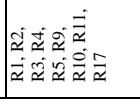 & 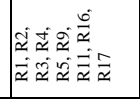 & 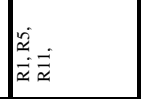 & & 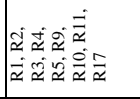 & 要 & 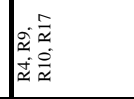 \\
\hline & & 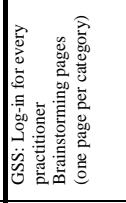 & 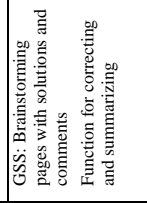 & 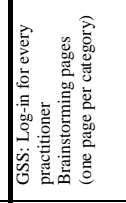 & 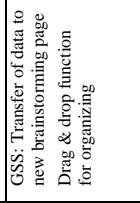 & 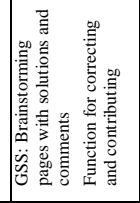 & 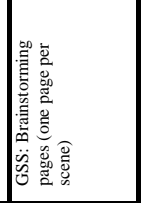 & 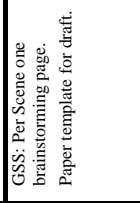 & 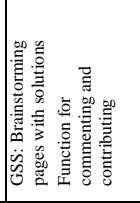 & 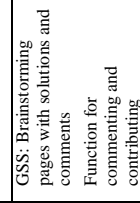 & 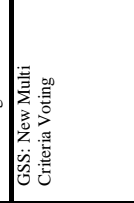 \\
\hline & & 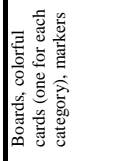 & 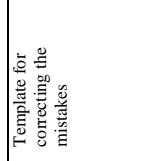 & 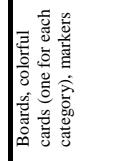 & 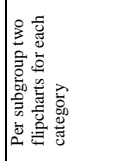 & & 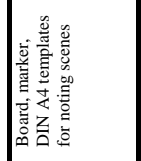 & $\frac{\pi}{50}$ & & & 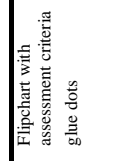 \\
\hline & & 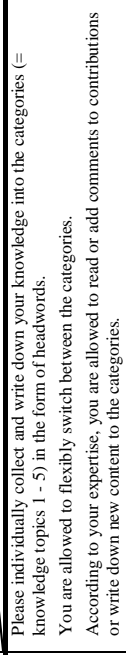 & 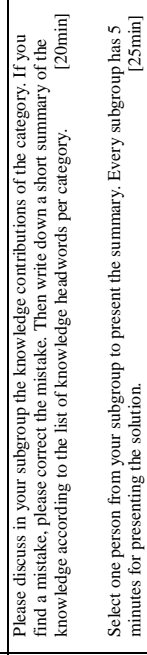 & 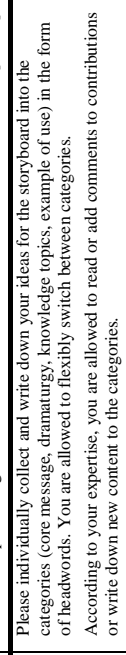 & 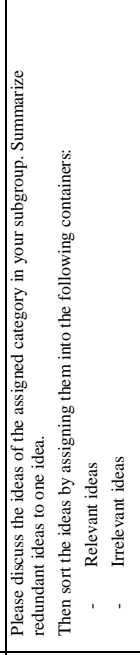 & 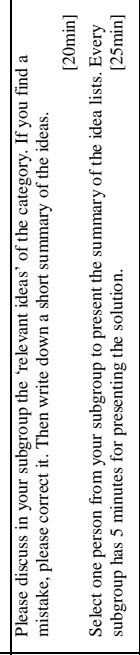 & 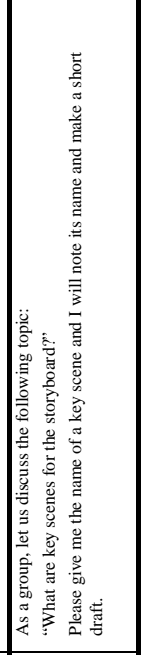 & 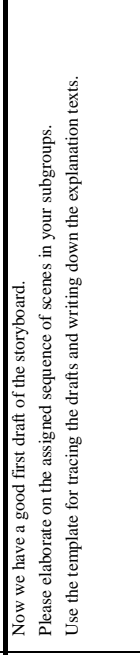 & 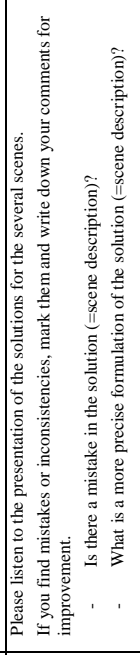 & 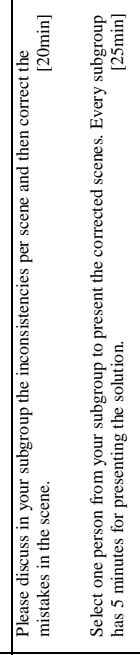 & 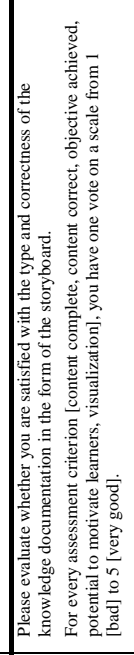 \\
\hline & 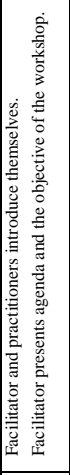 & 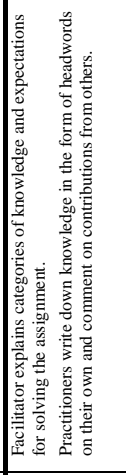 & 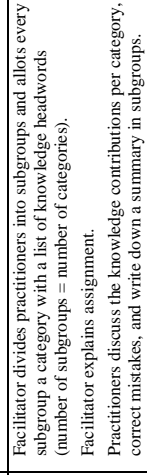 & 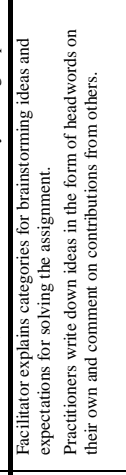 & 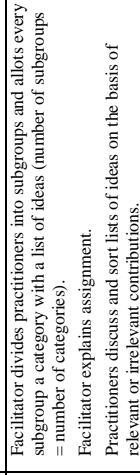 & 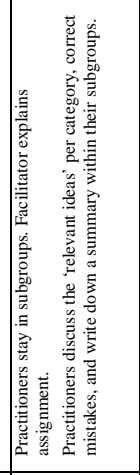 & 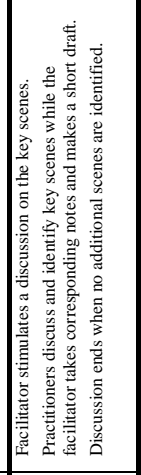 & 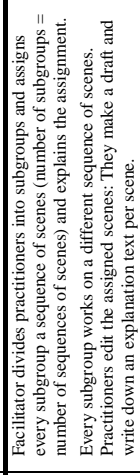 & 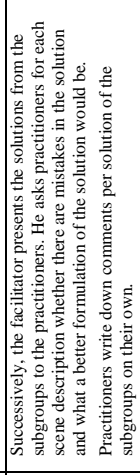 & 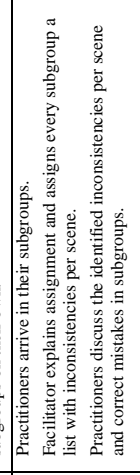 & 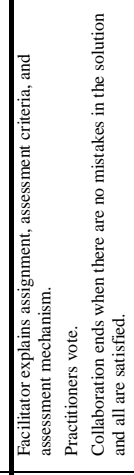 \\
\hline & & 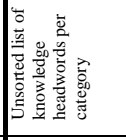 & 畜 & 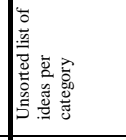 & 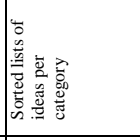 & 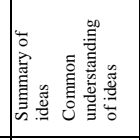 & 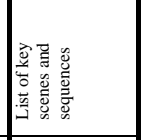 & 4 & & $\begin{array}{l}0.5 \\
\end{array}$ & 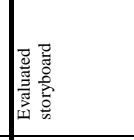 \\
\hline & & 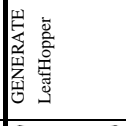 & 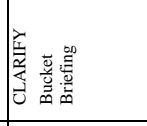 & 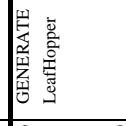 & $\ddot{0} \cong$ & 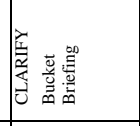 & 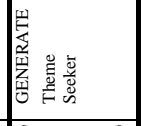 & 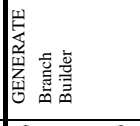 & 崖部 & $\overrightarrow{0}$ & 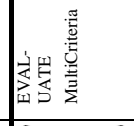 \\
\hline & & $\mid \begin{array}{ll}14 \\
\cdots\end{array}$ & $=$ & $\prod_{-\infty}$ & $\begin{array}{l}1 \\
=8\end{array}$ & 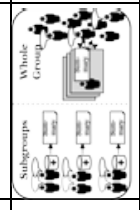 & i. & $\begin{array}{l}1 \\
0 \\
0 \\
0\end{array}$ & $1+0$ & 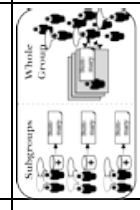 & {$\left[\begin{array}{ll}{[1} \\
{[}\end{array}\right.$} \\
\hline & 8 & ه & 䓃学 & حئ & ة̈ं & $\ddot{8}$ & $\ddot{8}$ & ة̈̈: & 8̈ & 8̈ & $\ddot{8}$ \\
\hline
\end{tabular}


The internal agenda (see Table 3 ) is more detailed and gives concrete hints on how to conduct the PCP. It refers to the formation of groups, the PoC and thinkLets, the several group products and activities, as well as the corresponding assignments and instructions. In order to illustrate that the same PCP design is applicable with different tool support, we provide a column for using paper-based tools as well as a column for using IT-based tools. In this way, we expand the internal agenda by addressing the two columns of tool support. In addition, the internal agenda depicts how the educational requirements are incorporated into the PCP design. The internal agenda itself addresses some educational requirements in general. For instance, R6 is addressed by defining a clear objective for the PCP. R7 and R8 are respected, since the PCP will be conducted by a facilitator who receives instructions for communicating expectations to the practitioners from the internal agenda. Overall, the internal agenda describes the assignments for the collaborative activities and illustrates the timeline. Accordingly, R13 to R15 are addressed generally.

\section{Evaluation of the peer-creation-process}

\subsection{Methodology}

In order to ensure a high quality of the PCP and to receive recommendations for applying the PCP with different tool support, we used an extensive design validation to evaluate and refine the PCP. We validated the PCP design during four iteration loops. After every loop, we took the PCP back into the field and tested it with real stakeholders, refined it, and developed a new version of the PCP for the next iteration (see Figure 4). Thereby, we iteratively passed through the CoPDA. We used an explorative analysis with qualitative and quantitative data [10].

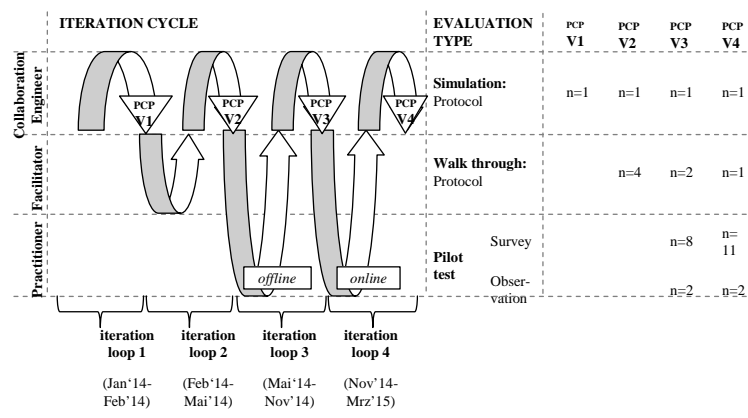

Figure 4. Iteration loops of PCP evaluation

Figure 4 depicts the four iteration loops and connects them with the several evaluation types we used and the amount of data we gathered by the three different groups of stakeholders. In that context, 'PCP V' illustrates the version of the PCP in the several loops.

Our data acquisition is characterized by testing the PCP with three groups of stakeholders during four iteration loops. In order to identify stumbling blocks, we conducted several design simulations of the PCP as the first requisite step in an iteration loop. In addition, we conducted several walk-throughs with facilitators (moderator and collaborative learning experts). The aim was to gain insights into improving the process design and determining whether the PCP could cope with educational requirements. By means of two pilot tests with practitioners, we gathered data from a survey as well as a participating observation. The pilot tests are the application of the PCP in a real-world setting in an IS Masters Course with learners who collaboratively transferred and documented their acquired knowledge about design methodology in the form of a storyboard. In order to gain insight into how to apply the same PCP with different tool support, 'PCP V2' was conducted with paper-based tools, while 'PCP V3' was conducted with a group-support-system (GSS) as IT-based tool support (see Table 3). The structure of every pilot test comprised a pre-test and a post-test with practitioners attending the PCP. In each case, the pre- and posttests consisted of a knowledge test (true/falsequestions) and a survey with questions addressing the self-reported knowledge level as well as items for evaluating the process design from the practitioners' points of view, according to Briggs et al. [32]. In order to interpret the qualitative data, we used a qualitative content analysis, according to Mayring [10]. In order to analyze the quantitative data, we used a descriptive data analysis.

\subsection{Results}

In the following we first discuss the results of the qualitative data analysis. Second, we discuss the results of the descriptive data analysis. Figure 5 refers to the qualitative data analysis, depicting the category system of the content analysis and its coding guideline. The category system consists of four main categories. These reflect the four iteration loops. The subcategories for each iteration loop reflect the quality criteria for evaluating the PCP from a facilitator's point of view [13]. To ensure traceability, we developed a coding guideline [10], mainly referring to the quality criteria for evaluating the PCP. Accordingly, in every iteration loop we analyzed whether the PCP addressed the quality criteria depicted in Figure 5. 

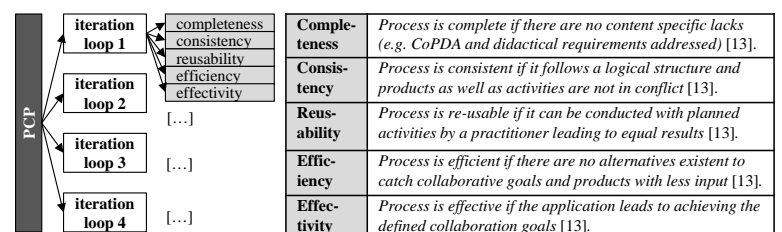

Figure 5. Category system and coding

In the following, we refer to the most important insights for each iteration loop: In iteration loop 1, we first designed collaborative learning activities with CE mechanisms. The granularity of the version 'V1' was high, because collaborative learning activeties were designed not using existing thinkLets. Nevertheless, the simulation acknowledges the evaluation criteria: expect the criteria of reusability since the PCP was not conducted with practitioners at this time. Iteration loop 2 inter alia consists of a walkthrough. This discloses insights for the consistency of the PCP which address formation of groups and assignment wording. A facilitator noted "[...] when do the learners work in groups? [...] what shall the learners do for solving an assignment?" Thus, for 'V2' we refined the comprehensiveness of the assignment wording and assignment structure, as well as reducing the number of group formation changes. This led to insights for designing the whole PCP by using existing thinkLets. Additionally, the facilitators assumed that the PCP was effective as they noted "[...] it will work and the participants will be excited!" Within iteration loop 3 , the pilot test led to insights for the completeness criteria concerning educational claims for the knowledge transfer. The collaboration between the practitioners was very close and was characterized by active discussions. In iteration loop 4, we changed the tool support and conducted the PCP by means of using a GSS. The evaluation criteria were acknowledged, but the group dynamics were changing. The closeness between the facilitator and the practitioners was not as close as that in loop 3, and there were a few unprofessional contributions from some of the practitioners.

Table 4 depicts the results of the descriptive data analysis, consisting of a comparison of the pilot test results from the iteration loops 3 and 4 . The results give insights into how practitioners experience the PCP, what their knowledge levels are, and which differences occur when changing the tool support. The results of constructs evaluating the PCP design have in both groups a high mean on a 5-point likert scale. In the offline group they are better compared to those in the online group. Contrasting the data from the pre-test to the post-test for knowledge transfer, the constructs for self-reported knowledge level show similar results. The knowledge transfer works in offline as well as online settings, since the results of the post-tests are better than those of the pre-tests. Regarding the PCPs potential to stimulate knowledge gain, the results from the knowledge tests show a knowledge gain in the post test as well. Nevertheless, to positively increase the experience of the PCP in the online setting, further adaptations are necessary.

Table 4. Evaluation results of the pilot tests

\begin{tabular}{|c|c|c|c|c|c|c|c|}
\hline & \multicolumn{3}{|c|}{$\begin{array}{l}\text { Iteration loop } 3 \text { (Offline) } \\
\qquad \begin{array}{l}\mathrm{N}=8 \\
\end{array}\end{array}$} & \multicolumn{3}{|c|}{$\begin{array}{l}\text { Iteration loop } 4 \text { (Online) } \\
\qquad N=11\end{array}$} \\
\hline \multirow{6}{*}{ 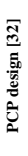 } & & \multicolumn{3}{|c|}{ Mean (SD) } & \multicolumn{3}{|c|}{ Mean (SD) } \\
\hline & SP - Satisfaction with Process & \multicolumn{3}{|c|}{$4.33(0.44)$} & \multicolumn{3}{|c|}{$2.76(0.87)$} \\
\hline & SO - Satisfaction with Outcome & \multicolumn{3}{|c|}{$4.35(0.45)$} & \multicolumn{3}{|c|}{$2.73(1.23)$} \\
\hline & TOOLDIF - Perceived Tool Difficulty & \multicolumn{3}{|c|}{$4.43(0.47)$} & \multicolumn{3}{|c|}{$3.73(0.45)$} \\
\hline & PROCDIF - Perceived Process Difficulty & \multicolumn{3}{|c|}{$3.78(0.61)$} & \multicolumn{3}{|c|}{$3.38(0.49)$} \\
\hline & \multicolumn{7}{|l|}{ 5-Point LIKERT scale $(1=$ negative; 5} \\
\hline \multirow{6}{*}{ 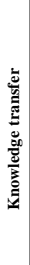 } & & Pre- test & Post-test & & Pre-test & Post-test & \\
\hline & & $\begin{array}{l}\text { Mean } \\
\text { (SD) }\end{array}$ & $\begin{array}{l}\text { Mean } \\
\text { (SD) }\end{array}$ & Spread & $\begin{array}{l}\text { Mean } \\
\text { (SD) }\end{array}$ & $\begin{array}{l}\text { Mean } \\
\text { (SD) }\end{array}$ & Spread \\
\hline & Knowledge test & $\begin{array}{l}67 \% \\
(0.52)\end{array}$ & $\begin{array}{l}71 \% \\
(0.64)\end{array}$ & $\uparrow 4 \%$ & $\begin{array}{c}72 \% \\
(0.52)\end{array}$ & $\begin{array}{c}76 \% \\
(0.63)\end{array}$ & $\uparrow 4 \%$ \\
\hline & Self-reported level of knowledge... & $\begin{array}{l}\text { Mean } \\
\text { (SD) }\end{array}$ & $\begin{array}{l}\text { Mean } \\
\text { (SD) }\end{array}$ & Spread & $\begin{array}{l}\text { Mean } \\
\text { (SD) }\end{array}$ & $\begin{array}{l}\text { Mean } \\
\text { (SD) }\end{array}$ & Spread \\
\hline & $\begin{array}{l}\text { a.) about kind of documenting knowledge } \\
\text { (storyboard development). }\end{array}$ & $\begin{array}{c}2.75 \\
(1.28)\end{array}$ & $\begin{array}{c}3.88 \\
(0.64)\end{array}$ & $\uparrow 1.13$ & $\begin{array}{c}2.10 \\
(0.57)\end{array}$ & $\begin{array}{c}3.40 \\
(0.84)\end{array}$ & $\uparrow 1.30$ \\
\hline & $\begin{array}{l}\text { b.) about procedural knowledge which } \\
\text { becomes transferred. }\end{array}$ & $\begin{array}{r}3.13 \\
(0.35)\end{array}$ & $\begin{array}{c}3.63 \\
(0.52)\end{array}$ & $\uparrow 0.50$ & $\begin{array}{r}3.40 \\
(0.52) \\
\end{array}$ & $\begin{array}{c}3.70 \\
(0.48)\end{array}$ & $\uparrow 0.30$ \\
\hline \multicolumn{8}{|c|}{ 5-Point LIKERT scale $(1=$ very less; $5=$ very high $)$} \\
\hline
\end{tabular}

\section{Discussion, limitations, future research}

The evaluation results are incorporated into the PCP design, since this was systematically redesigned during the design validation. Thus, the final PCP design contributes to $\mathrm{CE}$ literature in the research area of collaborative learning. Since the PCP design complies with educational requirements, a stimulation of knowledge transfer can be leveraged. The PCP is a new approach for solving the known problem of knowledge transfer. For this reason, we consciously choose the described way of design validation in order to gain deep insights. From a CE point of view, the required collaborative learning activities can be designed by combining existing thinkLets. This connotes that process designs can be developed in order to stimulate knowledge transfer by using CE mechanisms, also implying that requirements from collaborative learning can be indicated by means of using CE mechanisms. Table 4 depicts the PCP's potential to stimulate knowledge transfer and to increase a knowledge gain. There is a gain of practitioners' knowledge in both offline and online settings. By comparing the pre- and the post-tests, iteration loop 3 indicates an increase in the knowledge test results from $67 \%$ to $71 \%$, compared to an increase from $72 \%$ to $76 \%$ in iteration loop 4 . Furthermore, we asked the practitioners about their selfreported level of knowledge. We used a differentiated question, since the collaboration would result in a knowledge gain addressing procedural knowledge, 
whereas the type of knowledge documentation in the form of a storyboard would be something new for some practitioners. Similar to the results of the knowledge test, the results for the self-reported level of knowledge also increased. The increase in both the knowledge test results and the self-reported level of knowledge results on procedural knowledge leads us to believe that the practitioners experience the collaboration during the PCP to be valuable and that their self-assessment is, in fact, correct.

Another resulting benefit is the reusability of the PCP with different tool support. We analyzed the applicability of the same PCP design with changes in the tool support from a practitioners' as well as from a facilitators' point of view. By comparing the results of the knowledge transfer between loop 3 (offline) and loop 4 (online), we reason that an IT-supported collaboration leads to approximately the same results. In contrast, the practitioners using paper-based tools in iteration loop 3 are more satisfied with the process and the outcome and are more comfortable with the tools and the process difficulty. The different group dynamics can be an explanation for that phenomenon: Relationship between facilitator and practitioners: The atmosphere within the groups was different. Within the offline group the relationship between the facilitator and the practitioners was closer than that in the online group. An explanation is the different tool support requiring a different frequency of interactions by the facilitator. The interaction in the offline group was higher because the facilitator had more direct interactions with the practitioners, e.g., place cards and flipcharts. In contrast, in the online group the GSS took over these activities and the frequency of direct interactions between the facilitator and the practitioners decreased. The GSS replaced some of the instructions and moderating activities and practitioners worked more independently. This might have led to negative effects in terms of perceived satisfaction with the process and outcome. A lesson learned is that the facilitator has to look for other entries for directly interacting with the practitioners in an online setting in order to generate a positive group atmosphere. Anonymity of making contributions and relationship between practitioners: Furthermore, in the online setting the GSS allowed practitioners to make anonymous contributions. This led to a couple of unprofessional contributions which interrupted the process flow and the relationship between the practitioners. A lesson learned is that contributions in the GSS should not be anonymous in order to ensure accountability of practitioners' work and to avoid deviate contributions. Nevertheless, within the iteration loops there is an increase in the results for the knowledge transfer that sticks to a high level for both offline and online settings. This leads to the assumption that the same PCP design is applicable with different tool support. Since the results for the PCP design in the offline group are better than in the online group, we recommend expansions in the internal agenda for future research. The instructions for the facilitator need to be different. A section with differentiated instructions for enhancing a positive group atmosphere with a close relationship between facilitator and practitioners as well as among practitioners would be of value.

This study is not without limitations; however, we note that our focus is more on designing innovative solutions and gaining first insights. Even though the pilot tests with students have similar conditions to organizational settings, future research should evaluate the value of the PCP in an organizational setting. In our evaluation, practitioners had comparable levels of knowledge. Nevertheless, participating in the PCP led to a knowledge increase, even among practitioners on similar levels of knowledge. An evaluation with strong differences in the levels of knowledge of the practitioners, including experts as well as novices, would allow a more detailed analysis of the resulting knowledge transfer. Future research should also address a deeper analysis of the knowledge documents. The quality of the developed knowledge document is high since the practitioners review the knowledge document within the PCP. Consequently, the PCP includes a mechanism for correcting the knowledge document in the last activity. In order to strengthen the quality of the outcome, the focus of future research should be an evaluation of the knowledge document among lecturers. Finally, the focus of the paper was not to evaluate the indirect knowledge transfer to third parties. Thus, future research should assess the suitability of resulting knowledge documents for an indirect knowledge transfer to people who did not participate to the PCP.

\section{Conclusion}

In this paper, we showed how to design a PCP for leveraging the power of knowledge transfer that is also applicable with different tool support. The overall research approach is embedded in design science research. We derived a working definition of knowledge transfer and justified collaborative learning as crucial basics for knowledge transfer activities. Based on theory, we identified educational requirements and used the CoPDA as a design methodology for developing the PCP design. For the evaluation and refinement of the PCP, we conducted four iteration loops and used a differentiated design vali- 
dation with simulations, walk-throughs, and pilot tests. The results show that the PCP copes with educational requirements. It is applicable with, and without, IT-support and leverages a knowledge transfer. The results contribute to theory and practice. They provide insights into designing collaborative processes by respecting educational requirements in order to stimulate knowledge transfer. We show that collaborative learning activities can be structured in a reusable way. Further, the PCP gives insights into conducting the same process design with different tool supports. As a theoretical contribution, the PCP resembles a theory of design and action and a contribution of the type 'improvement' [7].

\section{Acknowledgements}

The research presented in this paper was partially funded by the German Federal Ministry of Education and Research in course of the project StaySmart (www.projekt-staysmart.de), FKZ 01FK14008.

\section{References}

[1] B. Schulz, "The Importance of Soft Skills: Education Beyond Academic Knowledge", Journal of Langugage and Communication 2008, pp. 144-154.

[2] P.A. David and D. Foray, "Economic Fundamentals of the Knowledge Society", Policy Futures In Education, 2003, vol. 1, pp. 1-23.

[3] A. King, "Structuring Peer Interaction to Promote HighLevel Cognitive Processing", Theory Into Practice, 2002, vol. 41, p. 34.

[4] I. Kollar, F. Fischer, and F. W. Hesse, "Collaboration Scripts", Educ. Psychol. Rev., 2006, vol. 18, pp. 159-185.

[5] B. Kopp and H. Mandl, "Fostering Argument Justification Using Collaboration Scripts and Content Schemes", Learning and Instruction, 2011, vol. 21, pp. 636-649.

[6] E.A.C. Bittner and J.M. Leimeister, "Creating Shared Understanding in Heterogeneous Work Groups: Why It Matters and How to Achieve It", JMIS, 2014, vol. 31, pp. 111-144.

[7] S. Gregor and A.R. Hevner, "Positioning And Presenting Design Science Research For Maximum Impact", MIS Quarterly, 2013, vol. 37, pp. 337-355.

[8] A.R. Hevner, "A Three Cycle View of Design Science Research", Scandinavian Journal of Information Systems, 2007, vol. 19, pp. 87-92.

[9] M. Sangin, G. Molinari, M.-A. Nüssli, and P. Dillenbourg, "Knowing What the Peer Knows", EC-TEL, Maastricht, The Netherlands, 2008.

[10] P. Mayring, "Qualitative Content Analysis", in A Companion to Qualitative Research, U. Flick, E.v. Kardorff, and I. Steinke, Eds., SAGE Publications Reinbeck, 2004, pp. 266-269.

[11] G.-J. de Vreede, R. O. Briggs, and A. P. Massey, "Collaboration Engineering: Foundations and Opportunities", JAIS, 2009, vol. 10, pp. 121-137.
[12] R.O. Briggs, G. Kolfschoten, G.-J. de Vreede, and D. Douglas, "Defining Key Concepts for Collaboration Engineering", 12 ${ }^{\text {th }}$ AMICS, Acapulco, Mexico, 2006.

[13] J.M. Leimeister, Collaboration Engineering. Springer Gabler, Berlin Heidelberg, 2014.

[14] G.L. Kolfschoten and G.-J. de Vreede, "A Design Approach for Collaboration Processes: A Multimethod Design Science Study in Collaboration Engineering", JMIS, 2009, vol. 26, pp. 225-256.

[15] D.R. Krathwohl, "A Revision of Bloom's Taxonomy", Theory Into Practice, 2002, vol. 41, pp. 212-218.

[16] I. Nonaka, "A Dynamic Theory of Organizational Knowledge Creation", Organization Science,1994,vol.5, pp.14-37.

[17] S. Oeste, M. Söllner, and J. M. Leimeister, "Engineering Peer-to-Peer Learning Processes for Generating High Quality Learning Materials", $20^{\text {th }}$ CRIWG 2014, Santiago, Chile, 2014.

[18] L.C. Moll, L.S. Vygotsky and Education. Taylor \& Francis, New York, 2013.

[19] M.G. Moore, "Editorial: Three Types of Interaction", American Jn. of Distance Education, 1989, vol. 3, pp. 1-7.

[20] G. Eisenkopf, "Peer Effects, Motivation, and Learning", Economics of Education Review, 2010, vol. 29, pp. 364-374.

[21] M.G. Moore, and G. Kearsley, Distance education: A Systems View of Online Learning. Wadsworth Publishing Company, Belmont, California, 2011.

[22] S. Oeste, K. Lehmann, A. Janson, and J.M. Leimeister, "Flipping the IS Classroom - Theory-Driven Design for Large-Scale Lectures", $35^{\text {th }}$ ICIS, Auckland, New Zealand, 2014.

[23] A. Harris, "Effective Teaching: A Review of the Literature", School Leadership \& Management: Formerly School Organisation, 1998, vol. 18, pp. 169-183.

[24] K.J. Topping, "Trends in Peer Learning", Educational Psychology 2005, vol. 25, pp. 631-645.

[25] T. Hall and A. Stegila, "Peer Mediated Instruction and Intervention", NCAC Classroom Practices, 2003.

[26] J. Parece, R. Mulder, and C. Baik, Involving Students in Peer Review Case Studies and Practical Strategies for University Teaching. Centre for the Study of Higher Education, 2009.

[27] C.-M. Chen and C.-H. Wu, "Effects of Different Video Lecture Types on Sustained Attention, Emotion, Cognitive Load, and Learning Performance", Computers \& Education, 2015, vol. 80, pp. 108-121.

[28] P. Dillenbourg, "What Do You Mean By Collaborative Learning", in Collaborative Learning, P. Dillenbourg, Ed., Elsevier Oxford, 1999, pp. 1-19.

[29] R.M. Gagné, "Learning Outcomes and Their Effects", American Psychologist, 1984, vol. 39, pp. 377-385.

[30] J.M. Jones, "Discussion Group Effectiveness is Related to Critical Thinking through Interest and Engagement", Psyc. Learning and Teaching,2014,vol.13, pp.12-24. [31] T.L. Leacock and J.C. Nesbit, "A Framework for Evaluating the Quality of Multimedia Learning Resources", Educ. Technology \& Society, 2007, vol. 10, pp. 44-59.

[32] R.O. Briggs, G.L. Kolfschoten, G.-J. de Vreede, S. Lukosch, and A.C.C., "Facilitator-in-a-Box ", JMIS, 2013, vol. 29, pp. 159-193. 